\title{
COMPARATISMO E ILUMINACIÓN RECÍPROCA DE LAS ARTES: MUSICA Y LITERATURA
}

Darío VILLANUEVA USC/RAE

principios del siglo siguiente al de las Luces en que escribió Lessing el Laooconte, en plena
irrupción del comparatismo en los diferentes apartados del saber, Sobry publicó un Cours
de peinture et littérature comparées (1810). Pero será un discípulo del gran historiador del Arte Heinrich Wölfflin, Oskar Walzel, quien en una conferencia programática de 1917 acuñe la expresión que mejor refleja esta modalidad comparatística: «la iluminación recíproca de las artes» («Wechselseitige Erhellung der Künste»), fórmula afortunada a la que ha acompañado también la noción de los «talentos dobles», los creadores que como Miguel Angel, Blake, Hoffmann, Wagner, Rossetti, Almada Negreiros, Dalí, Pier Paolo Pasolini o Federico García Lorca Lorca, se han expresado, además de literaria, plástica, musical o cinematográficamente, demostrando así, según Kurt Wais, la Symbiose der Künste (1936). Poco antes de la citada conferencia, Walzel había comenzado a trasladar a la literatura las categorías del Barroco y el Renacimiento que Wölfflin había definido en su libro sobre los conceptos fundamentales en la historia del arte, Kunstgeschichtliche Grundbegriffe, publicado en 1915.

Resulta obligado radicar en la facultad universal del lenguaje, y en su uso estético que constituye la literatura, el fundamento y origen de la disciplina de la Literatura comparada.

Cierto es, asimismo, que en la base de todas las artes está el principio aristotélico de la mimesis, pues la naturaleza humana se nos revela esencialmente mimética. Todas imitan y el objeto de su mimesis es el mismo: la realidad natural y la realidad humana. Pero cada una de ellas lo hace con instrumentos diferentes. $\mathrm{Y}$ es aquí donde encontramos de nuevo la razón de ser de los estudios interartísticos como ámbito privilegiado de la Literatura Comparada. El que en esta disciplina tenga cabida no solo la comparación entre la literatura escrita en una lengua y las escritas en otras sino también el estudio de las relaciones entre el arte de la palabra y las demás artes encuentra, asimismo, su razón de ser en la imitación.

Refuerza esta universalidad del comparatismo interartístico otro principio aristotélico, el de la catarsis, relacionado con la dimensión psicológica del fenómeno estético, con la emotividad del receptor de la artística y los efectos que esta provoca. 
Ya en 1719 el abbé Du Bos, en sus Réflexions critiques sur la poésie et sur la peinture, afirmaba que la fuerza mayor de la poesía y la pintura está en la imitación que hacen de objetos capaces de interesarnos y por ello «les poèmes et les tableaux ne sont de bons ouvrages qu'à proportion qu'ils nous émeuvent et nous attachent». Theodor Lipps hablaba también de una fusión simpática -Einfühlung- entre obra y receptor, en el marco de una verdadera estética subjetivista válida tanto para la literatura como para las otras cinco artes del catálogo establecido por los clásicos.

Ciertamente, estas consideraciones pertenecían tradicionalmente al ámbito de una disciplina filosófica, la Estética. La abstracción que la caracteriza no permite descender a consideraciones más puntuales, relacionadas con las distintas técnicas, procedimientos y recursos de cada una de las artes. La imitación de la realidad es común a todas ellas. Cambian, no obstante, los instrumentos que les son específicos, las formas. Y es aquí donde cabe la comparación como un método imprescindible para una comprensión cabal del fenómeno común de la mimesis en sus distintas expresiones artísticas. En términos actuales, diríamos que cambian los lenguajes, los signos que estudia esa otra disciplina omnicomprensiva que en la tradición europea del lingüista ginebrino Ferdinand de Saussure se denomina Semiología, y en la estela del filósofo norteamericano Charles Sanders Pierce es precisamente la Semiótica. Su distinción fundamental entre tres tipos de signos, los símbolos, los iconos y los índices es sumamente esclarecedora de las formas diferentes con que cada una de las artes imita la realidad. Resulta fundamental, pues, afrontar este campo de estudios interartístico desde la perspectiva de los que A.-M. Rousseau (1977: 50) califica como «un univers global de signes».

Hegel, en su Estética, situaba a la literatura en la cima jerárquica de todas las artes, por delante de la arquitectura, la escultura, la pintura, la música y la danza. La literatura era para el filósofo alemán el arte universal porque la imaginación constituye su elemento propio constitutivo, y la imaginación es la base general de todas las formas del arte y de todas las artes particulares.

A propósito de la pregunta que Claudio Guillén (1993: 124) se hace de si hoy por hoy el estudio de las relaciones entre la literatura y las demás artes debe desembocar en el comparatismo literario, Emilia Pantini (Gnisci 1999) aduce una interesante argumentación. Considera que esta disciplina constituye el ámbito más idóneo para estudiar estas relaciones porque la literatura es palabra y los vínculos entre las artes deben ser verbalizados. Pantini admite que la literatura no es totalizadora, ni puede arrogarse el estatus de un super-arte. Pero ciertamente es a través de la lengua, que es el medio de organización del pensamiento y de la comunicación común entre los humanos, como se produce la reflexión sobre todas las artes. En este sentido la literatura conduce el juego de las artes, y lo específico literario guía la reflexión sobre ellas.

La consolidación de esta línea interartística en las propias definiciones de la Literatura comparada como las de Henry H. H. Remak (1961) o A. Owen Aldidge (1969) obedece a la reflexión autocrítica que René Wellek (1963) exigió a la Literatura comparada en el segundo congreso de la AILC/ICLA. La reflexión sobre las relaciones entre las artes se colocó en el núcleo de la naturaleza y las tareas del comparatismo literario, pero esta requisitoria de 1958 no constituía una sorpresa viniendo de quien venía. No en vano, el capítulo undécimo de obra tan influyente como la Theory of Literature 
de Austin Warren y el propio René Wellek había sido dedicado ya en 1949 a la relación de la literatura con las demás artes y el crítico checo había publicado con anterioridad a poco de su llegada a los Estadoa Unidos un artículo sobre el paralelismo entre la literatura y las artes (Wellek 1941).

Se hizo perceptible, así, desde los primeros años sesenta del siglo XX un considerable incremento de este tipo de estudios entre los comparatistas. De 1963 data, por ejemplo, un libro fundacional de C. S. Brown, Music and Literature. A Comparison of the Arts; en los Estados Unidos MLA Bibliography introduce desde entonces este tema como uno de sus «General Topics», y en 1968 se recopila ya $A$ bibliography on the Relations of Literature and the Other Arts, 1952-1967 (New York: AMS Press).

El informe Bernheimer (1995: 41-2) acredita la vigencia de estos planteamientos en los años noventa al afirmar que «the space of comparison today involves comparisons between artistic productions usually studied by different disciplines», y algo semejante se puede afirmar para los comienzos del nuevo siglo. El nuevo informe de Haun Saussy (2006: 156) incluye un texto de Christopher Braider sobre «CL and the Visual Arts in Early Modern Studies» donde se parafrasea el título de un artículo de Erwin Panofsky publicado en 1955, «The History of Art as Humanistic Discipline», afrimando que la Literatura comparada lo es también por su atención no solo a las obras literarias sino también los otros «aesthetic artifacts» producidos por las otras artes.

Resulta, pues, evidente la consolidación y estabilidad de esta línea favorable a que el comparatismo debe atender también a las relaciones entre lo literario y lo artístico, filosófico, científico, ideológico o cultural en términos generales.

Una de las últimas glosas que Marshall McLuhan incluye al principio de uno de los capítulos de La Galaxia Gutenberg señala que la separación de la poesía y la música se reflejó por primera vez en la página impresa. Sería, pues, otra de las consecuencia de la implementación de una nueva tecnología, la de la imprenta de tipos móviles, al servicio de la escritura fonética que había abierto las puertas de la Historia en Mesopotamia 3.500 años de Cristo. Antes del alfabeto fonético la comunicación era fundamentalmente oral, y el paso de la tribu a la sociedad civil propiamente dicha no hubiese sido posible sin este nuevo sistema de fijación y transmisión de los contenidos.

Ciertamente, como L. Kramer (1984) recuerda en su libro sobre el tema, al principio existía la canción, y esta identificación entre música y poesía encuentra su fundamento en que ambas son artes únicamente dependientes de la organización inmediata, tangible, del transcurrir del tiempo. En este sentido, su fundamento estructural es el mismo, aunque el autor de Music and Poetry reconozca enseguida que no solo se ha avanzado poco en la búsqueda de un método interdisciplinar para su estudio comparativo sino que, hablando con franqueza, no existía ninguno a la altura de 1984, cuando Kramer escribe su tratado.

Sin embargo, desde 1972 el libro de N. Ruwet sobre lenguaje, música y poesía aporta un punto de referencia valioso para el estudio analítico de la obra musical y la literaria desde un principio metodológico común. Ruwet parte de un fundamento lingüístico formulado por Roman Jakobson, el de la proyección del eje paradigmático sobre el sintagmático que en caso de las secuencias poéticas produce una intensa concentración de recurrencias, los «couplings» de los que hablará luego Samuel 
R. Levin. De ahí que los fenómenos de repetición y variación o contraste sean determinantes en toda configuración estructural que tenga, como es el caso de los textos literarios y musicales, un desarrollo en el tiempo, idea que subyace asimismo a lo largo del libro de Brown (1963).

En todo caso, la intervención de Steven P. Scher (1980) en el IX congreso de la ICLA/AILC celebrado en Innsbruck, que incluía un llamamiento al enfoque semiológico de las relaciones entre ambas artes fue la antesala de una serie de interesantes aportaciones al tema como las de Barricelli (1988) o Piette (1987), sin olvidar las compilaciones de Cluk (1981), W. Steiner (1981) y Cellis (1982).

Pero aquella identificación entre música y poesía no se puede considerar en modo alguno excluyente de la que se da entre poesía y pintura desde mucho antes de la aparición de la imprenta. Igual que la disposición de las palabras, de las pausas, de los acentos, de los sonidos vocálicos y consonánticos, así como la distribución de las secuencias poéticas en hemistiquios, versos, estrofas o composiciones como el soneto obedecen a principios rítmicos basados fundamentalmente en la repetición y la variación, igualmente se puede jugar con el desarrollo verbal del poema para lograr efectos de armonía plástica y visual.

Las frases, los enunciados son líricos en muchos casos por lo sugerente de su significado y por la música que encierran las palabras y el ritmo de su secuencia, pero además la propia distribución del verso y las unidades que lo compongan en la página manuscrita o impresa nos conducen hasta el fenómeno poético que modernamente se ha plasmado en los caligramas de Guillaume Apolinaire: composiciones que además de aportar el significado líricamente coherente de sus palabras buscan una distribución tipográfica que sugiera un dibujo cuyo sentido tiene que ver con lo que el propio texto nos está diciendo, como sucede, por caso, en el poema titulado «Coeur, couronne et miroir».

Después de los caligramas de Apollinaire se consolidará una tendencia de la misma índole plasmada en la denominada poesía concreta o poesía visual, cultivada por ejemplo por el grupo brasileño Noigandres, inicialmente compuesto por Haroldo y Augusto de Campos junto a Décio Pignatari, autores en 1954 del manifiesto «Plan piloto para la poesía concreta», de la que será activo promotor en Europa el poeta boliviano-suizo Eugen Gomringer, cuyo manifiesto particular se titula «Vom vers zur konstellation».

Esta poesía concreta representa también una utilización de los signos visuales con un propósito poético empleando a veces simplemente palabras, aunque también hay una línea de esta poesía visual que se conoce como letrismo, fundado en los años cuarenta por el rumano Isidore Isou, en donde realmente el significado deja de existir porque no hay palabras sino simplemente letras, en lo que se da una coincidencia con formas del arte literario y pictórico oriental basadas en la caligrafía, aunque el valor acústico de los grafemas implique también el letrismo con la musicalidad. Pero lejos de representar estas tendencias caligramáticas o letrísticas aportes de la poesía de la vanguardia contemporánea, podemos encontrar sus precedentes en lo que los griegos llamaban «tejnopaijnía», es decir, poemas pintados, y los latinos «carmina figurata», poemas figurativos. Es muy conocido el poema de Simmias el Rodio que reproduce las alas de Eros y muchas veces, además, estos verdaderos 
caligramas clásicos o helenísticos tenían un propósito pragmático, porque eran poemas votivos, eran como ex-votos que se hacían a determinadas divinidades.

En todo caso, las relaciones entre palabra poética y música son abordadas ya en las Institutioni harmoniche (1558) de Gioseffo Zarlino y los tratadistas contemporáneo las abordan desde tres perspectivas complementarias. La primera tiene que ver con los aspectos puramente rítmicos y eufónicos. La segunda, con lo que los retóricos denominaban la dispositio de la obra, para nosotros la estructura, pues existen formas de composición de matriz musical que la literatura puede aprovechar tanto en el caso de la lírica como de la narrativa, a lo que presta especial atención el ya citado libro de C. S. Broen (1963). Y finalmente, está la problemática cuestión del significado de los signos poético y musical, de las palabras y de los sonidos, que son en ambos casos símbolos arbitrarios y convencionales salvo en el caso de la imitación armónica de los sonidos de la naturaleza por parte de los músicos o de las llamadas aliteraciones u onamatopeyas de que pueden hacer uso los poetas.

Siendo esto así, la identificación de los signos poéticos y musicales con lo que Peirce define como símbolos no nos impide establecer una gradación diferente ente unos y otros en cuanto a su arbitrariedad, convencionalidad y ambigüedad. La relación entre significante y significado es semánticamente mucho más expresiva en el caso de la literatura que en el de la música. Como recuerda E. Tarasti (1979: 30) parafraseando a Claude Lévi-Strauss, la música es lenguaje sin significado, lo que no implica que carezca radicalmente de él. Muy al contrario, posee una capacidad tan alta de implicar catárticamente al receptor que este proyectará sobre los sonidos que la canción, la sonata o la sinfonía le entregan un significado que no necesariamente será el mismo que les dé otro oyente.

Esta interpretación se observará que está muy próxima a la que la fenomenología literaria de Roman Ingarden nos da acerca del proceso por el que el lector de un texto literario lo recrea en toda su plenitud rellenando, por así decirlo, todos sus vacíos, resolviendo los «lugares de indeterminación» que caracterizan a la obra como el puro esquema de palabras -signos, por otra parte, arbitrarios- que en realidad es. Existe, pues, un amplio margen de discrecionalidad en la lectura que cada uno de nosotros haga de un mismo texto poético o narrativo, al que dotaremos intencionalmente de un significado que nace de nuestra propia sensibilidad, experiencia y enciclopedia cultural. Pero por muy amplia que sea esta discrecionalidad, la literatura siempre quedará muy lejos de la la profunda ambigüedad significativa que caracteriza a la música. Como concluye Lawrence Kramer (1984), el significado musical es siempre no predicativo e inexacto.

Muy próxima a esta noción fenomenológica de intencionalidad está lo que François Delalande denomina «conducta de escucha narrativa» que le sirve a Jean-Jacques Nattiez (1990) para justificar la posibilidad de una diégesis y una narrativa musical. Para el investigador canadiense, si intentamos hablar de relato musical, es a causa de la existencia de la dimensión sintáctica y temporal que la música comparte con la literatura, pero en definitiva es el oyente quien construye un hilo narrativo, si así lo desea, a partir de lo que se le da a escuchar. En consecuencia, una obra musical puede ser el punto de partida de un impulso narrativo, lo cual no llega a constituir por sí solo un relato. 
Resulta evidente que la vinculación más natural y genuina entre música y poesía se da en los orígenes de la lírica cuando el poema era canción. Ese maridaje nunca dejará de producirse hasta el hoy de los multitudinarios conciertos de los llamados cantautores, pero tuvo ciclos de especial esplendor como el de la Literatura liederista alemana, en cuyo vastísimo corpus destacan, por caso, numerosos poemas de Goethe musicados por Mozart, Beethoven, Schubert, Schumann o Liszt.

Son de destacar, asimismo, obras musicales que nacen a modo de glosa de poemas, como el «Prélude à l'après-midi d'un faune» de Claude Debussy inspirada en una égloga de Stéphane de Mallarmé. Y el recurso a cerrar con máxima intensidad el desarrollo de una gran obra orquestal con la incorporación al clímax sinfónico de un poema selecto está tanto en la novena de Beethoven y la «Ode an die Freude» de Friedrich Schiller como en «Eine Faust-Symphonie in drei Charakterbildern» de Franz Liszt o las sinfonías segunda y cuarta de Gustav Mahler.

En otros casos, la música aporta un esquema de composición tanto a poetas como a novelistas. Pensemos, así, en los Four Quartets de T. S. Eliot o en novelas de tan patente inspiración musical como La Symphonie Pastorale (1919) de André Gide o la posterior (1931) Sinfonía pastoral de Armando Palacio Valdés. Anthony Burgess publica también en 1984 su Napoleon Symphony. A Novel in Four Movements, después de que en 1962 hubiese abordado la imitación de la novena sinfonía de Beethoven en su novela A Clockwork Orange (1962) llevada al cine en 1971 por Stanley Kubrik.

La Sonata a Kreutzer (1889) de Leo Tolstoi se inspira en la partitura homónima escita para violín y piano por el propio Ludwig van Beeethoven, y esa forma de composición musical rige la concepción de las cuatro novelas amorosas de inspiración modernista el español Ramón del Valle Inclán Sonata de otoño (1902), Sonata de estío (1903), Sonata de primavera (1904) y Sonata de invierno (1905).

Un destacado estudioso de las relaciones entre música y literatura Jean-Jacques Nattiez (Alonso 2002: 119-147) ha analizado en detalle la composición fundamentada en el modelo de la fuga de la novela Prochain épisode publicada en 1965 por el escritor canadiense Hubert Aquin, y Leiling Chang (Alonso 2002: 149-186) la «novela musical» Concierto barroco (1974) cuyo autor, el cubano Alejo Carpentier, reconocido musicólogo, reconocía haberla compuesto con la «función tripartita» que está en el origen de la sonata y el concierto, aunque luego ambas formas puedan tener cuatro movimientos.

La inspiración musical está muy presente en la profunda renovación de la novela que caracteriza el Modernism internacional al que hay que adscribir a autores ya mencionados como el español ValleInclán o el francés Andrè Gide. En el capítulo III de la segunda parte de Les Faux-Monnayeurs (1925), titulado «Éduard expose ses idées sur le roman», este personaje novelista en el transcurso de una conversación sobre Bach con su maestro de música La Pérouse afirma que lo que desearía hacer en narrativa «c'est quelque chose que serait commme L'Art de la fugue».

Mención especial merece otra de las grandes obras del Modernismo novelístico, de título ya de por sí harto significativo: Point Counter Point (1928) de Aldous Huxley. El relato comienza con un concierto en Tantamount House en el que se interpreta la «Suite en si menor» del propio Bach y el narrador aprovecha la interpretación simultánea que cada instrumento hace de una misma partitura para teorizar acerca del relativismo de la realidad y el pluriperspectivismo de la novela. Point Counter 
Point se estructura, así, sobre la base del procedimiento musical que le da título, fundido con el de la fuga, y temáticamente sobre las dualidades antitéticas pasión/razón, cuerpo/espíritu que preocupaban entonces a Huxley, muy influido entonces por D. H. Lawrence, para quien la felicidad descansaba en la armonía de ambos elementos.

Este conflicto humano es su «tema inicial», que se desarrolla en sucesivas variaciones, generalmente encarnadas en un triángulo de personajes; uno de ellos, «agónico», se debate entre los dos polos; los otros dos, «rectilíneos» por decirlo en la terminología de Miguel de Unamuno, personifican tan solo uno de ellos, razón o pasión, en toda su pureza: Walter Bidlake y Marjorie / Lucy; Elinor y Philip Quarles / Everard Webley; Sidney Quarles y Rachel / Gladys, respectivamente, etc. Se unen de tal modo dos efectos contrapuntísticos en cada trío, la oposición interna en el personaje agónico y el contraste de los dos rectilíneos con él relacionados, a los que se añade el contrapunto constante a lo largo de toda la novela, el del equilibrado personaje Mark Rampion, trasunto del propio Lawrence.

Esta fecunda contaminación musical de la novela, a la que presta asimismo especial atención C. S. Brown (1963), alcanza a autores como Milan Kundera en obras como el Libro de la risa y del olvido -Kniha smíchu a zapomněni, 1979- o Insoportable levedad del ser-Nesnesitelná lehkost byti, 1984-. Con estos y tantos ejemplos más que podríamos aducir parece cumplirse desde la narrativa contemporánea aquel dictum de Walter Horatio Pater en su libro The Renaissance (1873): «All art constantly aspires towards the condition of music».

\section{Referencias bibliográficas}

Alonso, S., ed. (2002): Música y literatura. Estudios comparativos y semiológicos. Madrid: Arco/Libros.

BACKÈS, J. L. (1994): Musique et littérature. Paris: PUF.

BARRICELLI, J-P. (1988): Melopoiesis: Approaches to the Study of Literature and Music. New York: New York University Press.

BARRICELLI, J-P., y GIBALDI, J. (1982): Interrelations of Literature. New York: The Modern Language Association of America.

BERnHEIMER, Ch., ed. (1995): Comparative Literature in the Age of Multiculturalism. Baltimore \& London: The Johns Hopkins University Press.

Brown, C. S. (1963): Music and Literature. A Comparison of the Arts. Athens: The University of Georgia Press.

Brunel, P., y Chevrel, Y., eds. (1989): Précis de littérature compare. Paris, Presses Universitaires de France.

CAnudo, R. (1955): Manifeste des Septs Arts. Paris: Séguier.

CÉLIS, R., ed. (1982): Littérature et musique. Bruxelles: Facultés Universitaires Saint-Louis.

Cluk, N. A., ed. (1981): Literature and Music. Birmingham: Young University Press.

DoležEL, L. (1986): «Semiotics of Literary Communication», Strumenti Critici, 1. 1, pp. 5-48. 
(1990): Occidental Poetics. Tradition and Progress. Lincoln/London: University of Nebraska Press.

FISH, S. (1980): Is there a Text in this Class? The Authority of Interpretive Communities. Cambridge/London: Harvard University Press.

Genette, G. (1982): Palimpsestes. La Littérature au second degré. Paris: Du Seuil.

GNISCI, A., ed. (1999): Introduzione alla letteratura comparata. Edizioni Bruno Mondadori.

GROEBEN, N. (1977): Rezeptionsforschung als empirische Literaturwissenschaft. Kromberg/TS.: Scriptor.

GuILlÉn, C. (1993): The Challenge of Comparative Literature. Cambridge and London: Harvard University Press.

InGARDEN, R. (1931): Das Literarische Kunstwerk. Tübingen Max Niemeyer Verlag, $3^{\text {a }}$ ed.

IsER, W. (1978) : The Act of Reading: A Theory of Aesthetic Response. Baltimore: The Johns Hopkins University Press.

KonstantinOvic, Z. (ed.) (1981): Proceedings of the IXth Congress of International Comparative Literature Association, vol. III, Literature and the other arts. Innsbruck: Institut für Sprachwissenschaft der Universität.

KrAMER, L. (1984): Music and Poetry. Berkeley: University of California Press.

KRIEGER, M. (1992): Ekphrasis: The illusion of the Natural Sign. Baltimore: Johns Hopkins University Press.

Lagerroth, U., Lund, H. y Hedling, E., eds. (1997): Interart Poetics: Essays on the Interrelation of the Arts and Media. Amsterdam: Rodopi.

LESSING, G. E. (1987): Laokoon oder über die grenzen der Malerei und Poesie, Stuttgart: Reclam.

MARKIEWICZ, H. (1996): «Ut picture poesis. Dzieje toposu I problem», en Wymiary dziela literackiego. Cracow: Taiwpn Universitas.

Martin, S. (1978): Le langage musical. Sémiotique des systems. Paris: Éditions Klinscksieck.

McLuhan, M. (1962): The Gutenberg Galaxy: The Making of Typographic Man. Toronto: University of Toronto Press.

NAtTiEZ, J. J. (1975): Fondaments d'une sémiologie de la musique. Paris: Union Générale d'Editions. (1988): De la sémiologie à la musique. Montréal: Université du Québec à Montréal. (1990): «Can Someone Speak of Narrativity in Music?», Journal of the Royal Musical Association, 115, 2, 240-257.

PANOFSKY, E. (1955): Meaning in the Visual Arts. Chicago: University of Chicago Press.

PeIRCE, C. S. (1994): Peirce on Signs: Writings on Semiotic. James Hoopes, ed. Chapel Hill: University of North Carolina Press.

PETÖFI, J. S. (1974): «Tetxttheorie-Textverarbeitung. (Bemerkungen zu den Anwendungsmöglichkeiten einer partiellen Texttheorie in der Jurisprudenz)», en H. Brinckmann y K. Grimmer, comp., Rechstheorie und Linguistik. Referate und Protokolle der Arbeitstagung der WernerReimer-Stiftung. Bad Homburg: Gehlen. 
PiETTE, I. (1987): Littérature et Musique. Contribution à une orientation théorique (1970-1985). Namur: Presses Universitaires de Namur.

PraZ, M. (1975): Mnemosyne. The Parallel between Literature and the Visual Arts. Princeton: Princeton University Press.

RemaK, H. H. H. (1980): «The Future of Comparative Literature», en Köpeczi B., Vajda G. M., y Kovács, J., eds., Actes du VIIIe congrès de l'Association internationale de littérature comparée. Stuttgart: E. Bieber, vol. 2, pp. 429-437.

Riffaterre, M. (1994): «L'illusion d'ekphrasis», en G. Mathieu-Castellani, ed., La Pensée de l'image: Signification et figuration dans le texte et dans la peinture. Vincennes: PUV.

Rousseau, A-M. (1977): «Arts et Littérature: un état present et quelques réflexions», Synthesis, IV, pp. 31-51.

Ruwet, N. (1972): Langage, musique, poésie. Paris: Seuil.

SAussy, H., ed. (2006): Comparative Literature in an Age of Globalization. Baltimore: The Johns Hopkins University Press.

SCHER, S. P. (1980): «Comparing Literature and Music: Current Trends and Prospects in Critical Theory and Methodology», en Konstantinovic, Z., ed. (1980-82), Actes du IXe Congrès de l'Association Internationale de Littérature Comparée, vol. III, sec. B. Innsbruck: Institut für Sprachwissenschaft der Universität Innsbruck.

SCHMIDT, Siegfried J. (1980): Grundriss der empirischen Literaturwissenschaft. Band 1. Der gesellschaftliche Handlungsbereich Literatur. Braunschweig: Friedr. Vieweg \& Sohn Verlagsgesellschaft, 1980. English translation, (1982): Foundations for the Empirical Study of Literature. The Components of a Basic Theory. Hamburg: Helmut Buske Verlag.

STEINER, W. (1982): The Colors of Rhetoric. Chicago: University of Chicago Press. , ed. (1981): The Sign in Music and Literature. Austin: University of Texas Press.

TARAsti, E. (1979): Myth and Music. The Hague: Mouton.

Weisstein, U. (1978): «Literature and the Visual Arts», en Barricelli, J.-P. y Gibaldi, J., eds., Interrelations of Literature. New York: MLA, pp. 251-277.

WelleK, R. (1941): «The Parallelism between Literature and the Arts», English Institute Annual, pp. 29-63.

(1963): «The Crisis of Comparative Literature», en Concepts of Criticism. New Haven/London: Yale University Press., pp. 282-295.

WelleK, R. y WARREN, A. (1949): Theory of Literature. New York: Harcourt Brace.

WIENOLD, G. (1972): Semiotik der Literatur. Frankfurt/M.: Athenäum. (1979): «Vorüberlegungen zur Rolle des Konzepts der Textverarbeitung beim Aufbau einer empirischen Sprachtheorie», en Wolfgang Burghardt y Klaus Hölker, comp., Text Processing / Textverarbeitung. Berlin/New York: W. De Gruyter. 